\title{
Phenolic Constituents with Antioxidant and Antiviral Activities from Phyllanthus urinaria Linnea
}

\author{
Q. P. LIANG, C. WU1 1 , T. Q. XU, X. Y. JIANG ${ }^{2}$, G. D. TONG ${ }^{2}$, C. S. WEl' ${ }^{2 *}$ AND G. X. ZHOU*
}

Guangdong Province Key Laboratory of Pharmacodynamic Constituents of Traditional Chinese Medicine and New Drugs Research, Institute of Traditional Chinese Medicine and Natural Product, College of Pharmacy, Jinan University, Guangzhou 510632, ${ }^{1}$ Xiamen Key Laboratory of Biotechnology of TCM, Xiamen Medical College, Xiamen $361000,{ }^{2}$ National Key Special Department of Liver Diseases of TCM, Shenzhen Traditional Chinese Medicine Hospital, Guangzhou University of Chinese Medicine, Shenzhen 518033, China

\section{Liang et al:: Phenolic Constituents with Antioxidant and AntiHBV Activities from Phyllanthus urinaria}

Phyllanthus urinaria Linnea is commonly used in folk medicine with considerable therapeutic utility. Sixteen phenols of Phyllanthus urinaria were isolated from ethanol extract and their structures were identified by spectroscopic data. Oxygen radical absorbance capacity, radical scavenging assay and $\mathrm{HBsAg}$ and $\mathrm{HBeAg}$ ELISA kits were used to evaluate antioxidant and antiviral activities. All the isolates showed significant antioxidant activity. Especially, isolates 4 and 5 had the oxygen radical absorbance capacity of 5.12 and $8.13 \mathrm{U} / \mathrm{mol}$ and strong radical scavenging activity with $\mathrm{IC}_{50}$ values of 5.50 and $5.55 \mu \mathrm{M}$, respectively. Additionally, these studies also demonstrated that the compounds 1, 2, 11, 12, and 16 inhibited secretion of HBsAg and HBeAg in HepG2.2.15 cells. This study suggested that the phenolic constituents of Phyllanthus urinaria possessed antioxidant activities and these might play an important role in antihepatitic effects.

Key words: Phyllanthus urinaria Linnea, isolation and identification, phenolic constituents, antioxidant activity, antihepatitis $B$ activity

Phyllanthus urinaria Linnea (Euphorbiaceae) is an important traditional herb, which is widely used in subtropical area of Asia for liver protection, hepatitis, nephrolithiasis, dropsy, jaundice, and diabetes ${ }^{[1]}$. It has attracted more and more attention due to its ability to treat HBsAg carriers reported by Thyagarajan et al. ${ }^{[2]}$.

Contemporary pharmacological research reported that $P$. urinaria exhibited antioxidant activity and significantly reduced nitric oxide radicals associated with cell-mediated immune diseases ${ }^{[3]}$. Geraniin, a tannin from $P$. urinaria, was reported to exhibit semicarbazide-sensitive amine oxidase inhibitory, antioxidant, and antihypertensive activities ${ }^{[4]}$. Additionally, ethanol, methanol and acetone extracts of $P$. urinaria inhibited HSV-2 infection in vitro ${ }^{[5]}$. Ellagic acid, a phenolic molecule identified in $P$. urinaria, was reported to exhibit antihepatitis B virus activity through down-regulating hepatitis $\mathrm{B}$ virus (HBV) gene expression and decreasing the secretion of HBsAg and $\mathrm{HBeAg}$ in HepG 2 2.2.15 cell line ${ }^{[6]}$. Phyllanthin, phyltetralin, trimethyl-3,4dehydrochebulate, methylgallate, rhamnocitrin, methyl brevifolincarboxylate, $\beta$-sitosterol-3-O- $\beta$-D- glucopyranoside, quercitrin, and rutin were isolated from the ethanol extract of this plant for searching potent natural antiinflammatory agents, and their antioxidant, and antiinflammatory activities in vitro were assayed ${ }^{[7]}$. Recently, (4R,6S)-2-dihydromenisdaurilide (DHMD) as an efficient inhibitor of hepatitis $\mathrm{C}$ virus (HCV) entry as well as (-)-menisdaurilide was isolated from the plant, and its mechanism on antiHCV infection was investigated in vitro ${ }^{[7]}$.

Earlier phytochemical studies on P. urinaria indicated that its major constituents were tannins, flavonoids, lignans, coumarins, and polyphenols ${ }^{[8-12]}$. Among these compounds, a few compounds such as gallic acid, rutin, ellagic acid, and quercetin ${ }^{[13-16]}$ have sufficiently been studied. Some of small molecule polyphenols have also been confirmed possessing significant bioactivities, and their pharmacological activities may mainly stem

This is an open access article distributed under the terms of the Creative Commons Attribution-NonCommercial-ShareAlike 3.0 License, which allows others to remix, tweak, and build upon the work non-commercially, as long as the author is credited and the new creations are licensed under the identical terms

Accepted 15 March 2019

Revised 21 November 2018

Received 14 September 2018

Indian J Pharm Sci 2019;81(3):424-430 
from their free radical scavenging and their actions on cell signaling pathways ${ }^{[17,18]}$.

Although a series of chemical constituents and their activities from $P$. urinaria had been revealed earlier, further systematic phytochemical investigations and evaluations of biological activities are necessary for uncovering the fundamental constituents responsible for these therapeutic effects. The present study was aimed to investigate the phenol compounds from the ethanol extract of $P$. urinaria for potential antioxidant and antiviral activities. Isolation of 16 phenol compounds and the antioxidant and antiHBV activities exhibited by these are presented herein.

\section{MATERIALS AND METHODS}

High performance liquid chromatography (HPLC) was performed on an Agilent 1260 HPLC system equipped with an diode array detector, using column A (Ultimate XB-C18, $5 \mu \mathrm{m}, 4.6 \times 250 \mathrm{~mm}$, Welch, Potamac, MA, USA) for analysis and column B (Ultimate XBC18, $5 \mu \mathrm{m}, 10 \times 250 \mathrm{~mm}$, Welch, Potamac, MA, USA) for semi-preparative HPLC purification. Open column chromatography (CC) was conducted on silica gel (200-300 mesh, Haiyang Chemical Group Corporation, Qingdao, China) and Sephadex LH-20 (25-100 mm, Pharmacia, Uppsala, Sweden). HSGF254 silica gel thin-layer chromatographic (TLC) plates (Qingdao Marine Chemical, China) were used to chemical analysis of fractions. The spraying reagent used for TLC detection was $10 \% \mathrm{H}_{2} \mathrm{SO}_{4}$ in ethanol. All nuclear magnetic resonance (NMR) spectra were carried out on Bruker AV-300 spectrometer (Bruker Instrument, Inc, Zurich, Switzerland). High-resolution electrospray ionization mass spectrometry (HR-ESIMS) was achieved on an Agilent 6210 LC/MS TOF mass spectrometer (Agilent Technologies, Santa Clara, CA, USA). UV spectra were recorded on a Jasco V-550 UV/Vis spectrometer (Jasco Corporation, Tokyo, Japan). The optical rotations were recorded on a Jasco digital polarimeter (Jasco Corporation, Tokyo, Japan) using a thermostable optical glass cell.

Fluorescein sodium salt, 2,2'-azobis (2-methylpropionamidine) dihydrochloride (AAPH), 6-hydroxy-2,5,7,8-tetramethylchroman-2-carboxylic acid (Trolox) were purchased from Macklin (Shanghai, China). Dulbecco's modified Eagle's medium (DMEM), heat-inactivated fetal bovine serum (FBS), penicillin $A$ and streptomycin were purchased from Gibco (USA). Thermo Scientific Multiskan GO Microplate Spectrophotometer (Thermo Scientific,
USA) and GENios Microplate System and Magellan work station (Tecan, Switzerland) were used for oxygen radical absorbance capacity (ORAC) and 2,2-diphenyl-1-picrylhydrazyl (DPPH assays). All the other reagents and solvents were provided by Tianjin Damao Chemical Company (Tianjin, China).

\section{Plant material:}

The plant material was provided by Shenzhen Hospital Affiliated to Guangzhou University of Chinese Medicine, Shenzhen, China, and authenticated in the Department of Pharmacognosy, College of Pharmacy, Jinan University. A voucher specimen (no. 20110901) was also deposited in the department.

\section{Extraction and isolation:}

Ten kilograms of the dried and ground material of P. urinaria was soaked in $95 \%$ ethanol and extracted by percolation method. The extract (900 g) was obtained from the soaked solution after evaporation of the solvent. The extract was suspended in distilled water and partitioned successively with petroleum ether, chloroform, and ethyl acetate (EtOAc). The EtOAc extract $(130 \mathrm{~g})$ was subjected to silica gel $\mathrm{CC}$ eluting with $\mathrm{CHCl}_{3}-\mathrm{CH}_{3} \mathrm{OH}$ (100:0 to $\left.0: 100\right)$ in gradient to yield 8 fractions after combining based on TLC patterns. Various chromatographic (TLC, silica gel, Sephadex LH-20, ODS and HPLC) and spectroscopic methods (NMR, MS, UV) were used for the isolation and structural identification of compounds.

\section{Cell lines and cell culture:}

HepG2.2.15 cells (a HBV-transfected human HepG2 cell line) and HepG2 cells were cultured in DMEM medium with $10 \% \mathrm{FBS}$ and $1 \%$ antibiotic mixture containing 100 units $/ \mathrm{ml}$ penicillin A and 100 units $/ \mathrm{ml}$ streptomycin in a humidified incubator with $5 \% \mathrm{CO}_{2}$ at $37^{\circ}$.

\section{Antihepatitis B virus effect in vitro:}

HepG2.2.15 cells $\left(2 \times 10^{4}\right.$ cells/well $)$ were seeded in 24-well plates. After $48 \mathrm{~h}$ incubation, cells were treated with the absence or presence of various concentrations of samples for $6 \mathrm{~d}$, and the culture medium was refreshed every $3 \mathrm{~d}$ by fresh drug containing medium. Meanwhile, the supernatants on day 3 and day 6 were harvested to determine the concentration of $\mathrm{HBsAg}$ and $\mathrm{HBeAg}$ using an ELISA kit. Lamivudine (3TC) was used as positive control and the absence of sample was served as blank control. Each test was carried in 
triplicate, and the HepG2 cells were used for testing cell viability using MTT assay.

\section{Antioxidant activity test:}

ORAC assay was applied for evaluating the antioxidant activity of each compound ${ }^{[19,20]}$. Briefly, $20 \mu \mathrm{l}$ of $10 \mu \mathrm{M}$ samples to be tested or $20 \mu \mathrm{M}$ Trolox, dissolved in phosphate-buffered saline (PBS), were transferred to each well. One hundred and forty microliters of final concentration of AAPH and $20 \mu \mathrm{l}$ of final concentration of $63 \mathrm{nM}$ fluorescein sodium salt were rapidly added to the reaction system in the dark. Fluorescence was immediately read at $538 \mathrm{~nm}\left(\lambda_{\mathrm{ex}}: 485 \mathrm{~nm}\right)$. The decrease of fluorescence values were recorded every $2 \mathrm{~min}$ at $37^{\circ}$ with $5 \mathrm{~s}$ stirring before measurement until no fluorescence was detected in sample. The total volume of the reaction system was supplied to $200 \mu \mathrm{l}$ by PBS and the Trolox was served as internal control. The area under the curve (AUC) was calculated using the Eqn. below, AUC $=2 \times\left(\mathrm{f}_{0}+\mathrm{f}_{1}+\ldots+\mathrm{f}_{\mathrm{n}-1}+\mathrm{f}_{\mathrm{n}}\right)-\mathrm{f}_{0}-\mathrm{f}_{\mathrm{n}}$, where $\mathrm{f}_{0}$ is the initial fluorescence at $0 \mathrm{~min}$, and $\mathrm{f}_{\mathrm{n}}$ is the fluorescence read at corresponding time. The net AUC is equal to the difference value between the AUC of the blank and each sample. ORAC values were calculated as, ORAC value $=\left(\right.$ net $\mathrm{AUC}_{\text {sample }} /$ net $\left.\mathrm{AUC}_{\text {Trolox }}\right) \times($ molarity of Trolox/molarity of sample).

\section{DPPH assay:}

The radical scavenging activity was determined using the DPPH method in a microtiter plate ${ }^{[20,21]}$. Twenty microlitres of various concentrations of test samples diluted in methanol (0-30 $\mu \mathrm{M}$ final concentration) and $180 \mu \mathrm{l}$ of $150 \mu \mathrm{M}$ DPPH solution in methanol were added to 96 -well microtiter plate. The mixture was incubated for $30 \mathrm{~min}$ in the dark with shaking before readings were taken. Quercetin served as a positive control, and sample was substituted by methanol in the blank. For each test, the loss on the absorbance was measured, and the DPPH radical scavenging rate (S \%) was calculated in the following Eqn., $\mathrm{S} \%=$ $\left(\mathrm{Abs}_{\text {blank }}-\mathrm{Abs}_{\text {sample }}\right) / \mathrm{Abs}_{\text {blank }}$, where $\mathrm{Abs}_{\text {sample }}$ and $\mathrm{Abs}_{\text {blank }}$ are the absorbance of the DPPH radical solution incubated with or without the tested sample. For each compound, four concentrations were evaluated.

All the biological assays on antihepatitis B virus effect in vitro, antioxidant activity test with ORAC and DPPH methods were done from 2016 to 2017.

\section{Statistical analysis:}

All values were presented as means $\pm \mathrm{SD}$. One- way ANOVA was used to evaluate the data statistic differences using Prism 6 software. At least three independent tests were performed for all assay condition.

\section{RESULTS AND DISCUSSION}

Sixteen phenolic compounds were obtained from $P$. urinaria extract, their structures were identified by spectroscopic methods including ${ }^{1} \mathrm{H},{ }^{13} \mathrm{C} \mathrm{NMR}$, and ESI-MS, and comparison with the data reported in previous studies (fig. 1). These were identified to be emodin-8-O- $\beta$-D-glucopyranoside $(1)^{[22]}$, catechin (2), epicatechin (3), chebulanin (4) ${ }^{[23]}$, albibrissinoside $\mathrm{B} \quad(5)^{[24]}, \quad(-)-(2 R)-1-O-\beta$-D-glucopyranosyl-2- $\{2-$ methoxy-4-[(E)-formylvinyl]phenoxyl $\}$ propane3-ol $\quad(6)^{[25]}, \quad(+)$-pinoresinol $\quad(7)^{[26]}, \quad 3,4,8,9,10$ pentahydroxydibenzo[b,d]pyran-6-one $\quad(8)^{[27]}$, brevifolin (9) ${ }^{[28]}$, gallic acid (10) ${ }^{[29]}, 3-O$-methylgallic acid $(11)^{[30]}$, ethyl gallate $(12)^{[29]}$, ferulic acid $(13)^{[31]}$, caffeic acid $(14)^{[32]}, p$-coumaric acid $(15)^{[33]}$, protocatechuic acid $(16)^{[32]}$. All of these compounds except isolate 10 were isolated from this plant for the first time. These compounds are all phenols due to the presence of phenol group $(\mathrm{OH})$ in their structures, and most of them are polyphenols with two or more phenolic OHs.

The antiviral activity against hepatitis $B$ virus of compounds 1-2, 4-7, 10-12, and 16 were investigated in vitro using ELISA assay, and the results were summarized in Table 1. The phenols tested in experiment showed potential antiHBV activity with stronger capacity against $\mathrm{HBs} \mathrm{Ag}$ secretion than $\mathrm{HBeAg}$ secretion at the third day or sixth day. Among them, compounds 1, 2, 11, 12 and 16 were the most active ones. They significantly inhibited HBsAg and HBeAg secretion at the maximum noncytotoxic concentration and showed stronger inhibition than the positive control lamivudine (3TC).

Antioxidant activities of isolates 1-12 and 15-16 were tested using the ORAC assay. According to the result of ORAC assay (Table 2), the isolated compounds 2, 4, 5, 11 and 15 exhibited obvious antioxidant activities with the ORAC values of 4.54, 5.12, 8.13, 4.85 and $4.88 \mathrm{U} / \mathrm{mol}$. The curves of their relative fluorescence intensity were shown in fig. 2, and they were even stronger than the positive control quercetin. Compound 5 was the strongest antioxidant among them.

The main mechanism of phenolic antioxidants is free radical scavenging. These isolates were evaluated using 


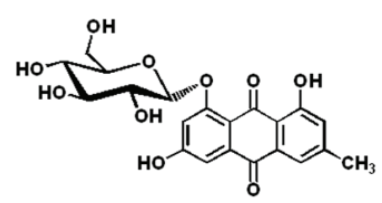<smiles></smiles><smiles>Oc1cc(O)c2c(c1)OC(c1ccc(O)c(O)c1)C(O)C2</smiles>

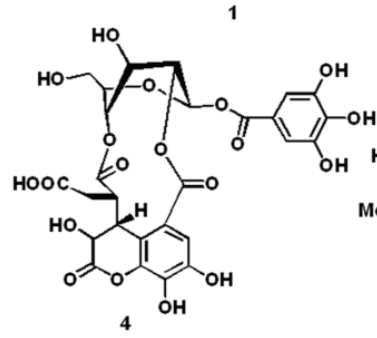

2
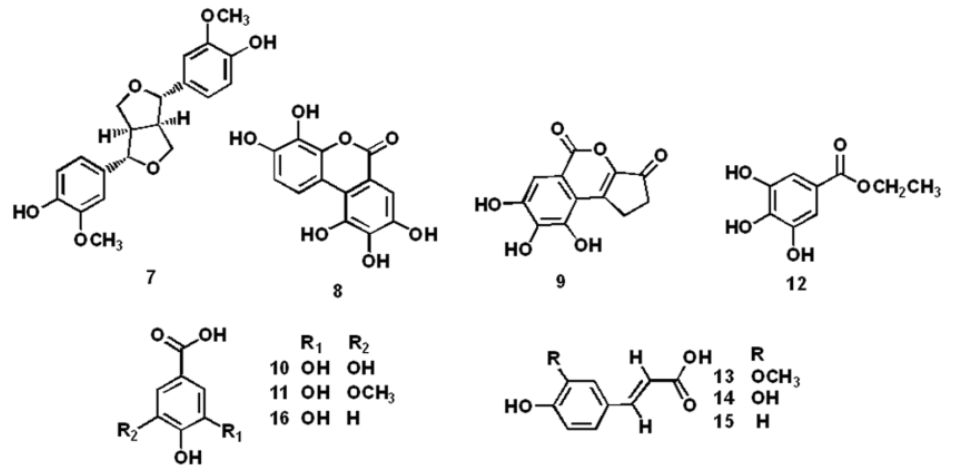

Fig. 1: Structures of the compounds 1-16

\section{TABLE 1: ANTIHEPATITIS B VIRUS ACTIVITIES OF COMPOUNDS}

\begin{tabular}{|c|c|c|c|c|c|c|}
\hline \multirow{2}{*}{ Compound } & \multirow{2}{*}{$\mathrm{CC}_{0}$ in HepG 2} & \multirow{2}{*}{$\begin{array}{c}\text { Concentration } \\
(\mu M)\end{array}$} & \multicolumn{2}{|c|}{ Inhibition of HBsAg (\%) ${ }^{a}$} & \multicolumn{2}{|c|}{ Inhibition of $\mathrm{HBeAg}(\%)^{a}$} \\
\hline & & & Day 3 & Day 6 & Day 3 & Day 6 \\
\hline 1 & $>100$ & 100 & $28.41 \pm 3.30$ & $41.20 \pm 0.82$ & $11.87 \pm 1.00$ & $22.19 \pm 6.06$ \\
\hline 2 & $>100$ & 100 & $14.82 \pm 4.33$ & $30.80 \pm 2.34$ & $4.17 \pm 0.10$ & $45.82 \pm 3.84$ \\
\hline 4 & $66.61 \pm 2.35$ & 50 & - & $8.09 \pm 1.00$ & - & $18.60 \pm 1.09$ \\
\hline 5 & $>100$ & 100 & - & $8.90 \pm 3.58$ & - & $26.05 \pm 5.43$ \\
\hline 6 & $>100$ & 100 & - & $5.61 \pm 1.81$ & - & $17.22 \pm 1.88$ \\
\hline 7 & $>100$ & 100 & - & $11.56 \pm 3.62$ & - & $17.71 \pm 1.23$ \\
\hline 10 & $106.93 \pm 5.29$ & 100 & $1.22 \pm 0.21$ & $12.63 \pm 0.19$ & $10.83 \pm 1.51$ & $15.48 \pm 1.57$ \\
\hline 11 & $109.69 \pm 1.39$ & 100 & $20.45 \pm 2.87$ & $26.13 \pm 0.61$ & $10.44 \pm 1.89$ & $24.88 \pm 0.36$ \\
\hline 12 & $26.75 \pm 2.86$ & 25 & $21.69 \pm 2.32$ & $30.95 \pm 3.82$ & $3.93 \pm 0.21$ & $26.48 \pm 5.75$ \\
\hline 16 & $>100$ & 100 & $20.68 \pm 8.26$ & $21.73 \pm 4.16$ & $4.88 \pm 0.44$ & $32.17 \pm 1.75$ \\
\hline $3 \mathrm{TC}^{b}$ & - & 500 & $17.26 \pm 1.97$ & $22.14 \pm 2.17$ & $6.73 \pm 0.33$ & $12.31 \pm 2.11$ \\
\hline
\end{tabular}

'-'Means no test because of the limit of amounts; the compounds 3, 8, 9, 13, 14 and 15 are no tested as their limit of amounts; ' ${ }^{a}$ 'mean percent inhibition values $\pm S D(n=9)$; ' $b$ ' used as positive control

the DPPH radical scavenging assay with quercetin as the positive control. Results of the scavenging activity were demonstrated by the $\mathrm{IC}_{50}$ values, which were presented in Table 2. Additionally, the fig. 3 implied that compounds 4, 5, 9, 10,11 and 12 indicated strong DPPH radical scavenging activity.

As a traditional antihepatitis herb in Eastern Asia, P. urinaria is rich in polyphenol compounds as reported in various phytochemical investigations earlier ${ }^{[4-11]}$. These investigations included the quantitative and qualitative analysis of phytochemical ingredients such as the location and confirmation of active extracts ${ }^{[34-36]}$, and isolation of some compounds, even new natural products $^{[4,5,9-11]}$ from this plant. It is worthy to report that research involving bioactivity-guided purification of $P$. urinaria led to the discovery of a HCV entry inhibitors loliolide ${ }^{[37]}$ and DHMD $^{[7]}$. Furthermore, ellagic acid from $P$. urinaria, which effectively suppressed the HBeAg secretion in HepG2 2.2.15 cells as a novel antiHBV compound ${ }^{[7]}$. These studies showed 
TABLE 2: ANTIOXIDANT ACTIVITIES OF COMPOUNDS MEASURED BY ORAC AND DPPH ASSAYS

\begin{tabular}{lcc}
\hline Compound & ORAC $(\mathrm{U} / \mathrm{mol})^{a}$ & $\mathrm{IC}_{50}(\mu \mathrm{M})^{b}$ \\
\hline 1 & $2.30 \pm 0.02$ & $>50$ \\
2 & $4.54 \pm 0.03$ & $>50$ \\
3 & $1.22 \pm 0.04$ & - \\
4 & $5.12 \pm 0.29$ & $5.50 \pm 0.09$ \\
5 & $8.13 \pm 0.23$ & $5.55 \pm 0.08$ \\
6 & $0.82 \pm 0.02$ & $>50$ \\
7 & $2.50 \pm 0.15$ & $>50$ \\
8 & $1.90 \pm 0.09$ & - \\
9 & $2.06 \pm 0.10$ & $10.16 \pm 0.16$ \\
10 & $2.73 \pm 0.02$ & $6.25 \pm 0.16$ \\
11 & $4.85 \pm 0.11$ & $13.26 \pm 0.17$ \\
12 & $2.91 \pm 0.12$ & $6.14 \pm 0.10$ \\
15 & $4.88 \pm 0.12$ & $>50$ \\
16 & $2.63 \pm 0.18$ & $32.28 \pm 0.10$ \\
Quercetinc & $2.59 \pm 0.14$ & $8.64 \pm 0.10$ \\
\hline${ }^{c}{ }^{\prime}$ Mean ORAC values $\pm S D(\mathrm{n}=9) ;$ ' $b$ 'the concentration of tested \\
compounds required to scavenge $50 \%$ of DPPH radicals; 'c'used as \\
positive control. Note: $U$ was equivalent Trolox of 1 mol; '-' means \\
no test because of the limit of amounts; the compounds 13 and 14 \\
were not tested due to limited availability
\end{tabular}

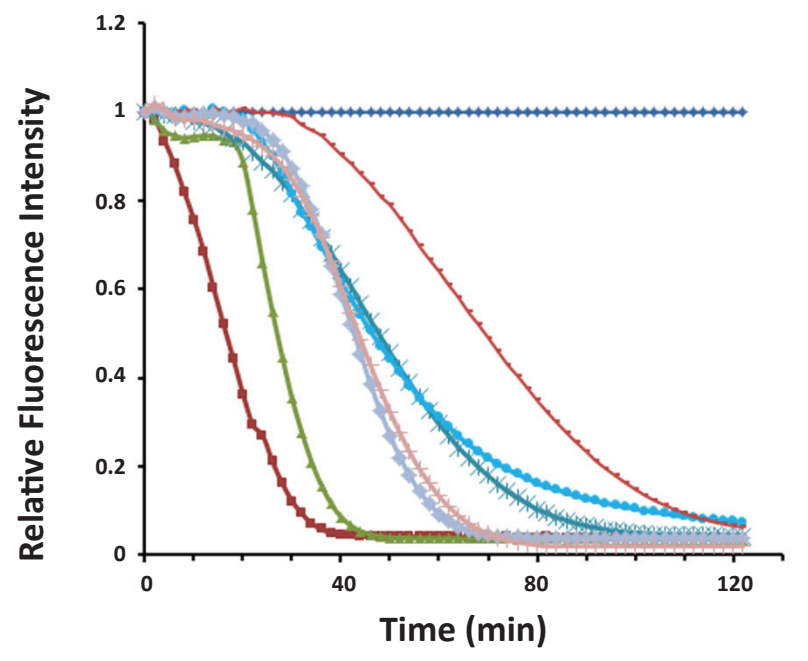

Fig. 2: Fluorescence curves in the presence of compounds 2, 4, 5,11 and 15

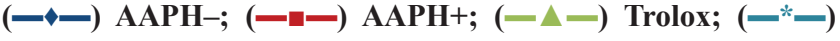
compound $2 ;(-\bullet-)$ compound $4 ;(-)$ compound $5 ;(-\bullet-)$ compound $11 ;(-\mathrm{I}-)$ compound 15

that $P$. urinaria contained many complex and diverse constituents with potent biological activity, especially the phenolic compounds, which exhibited various biological activities such as antioxidant ${ }^{[18]}$, antiviral ${ }^{[38]}$, antitumor $^{[39]}$.

Our previous investigations on $P$. urinaria reported isolation of a series of flavonoid glycosides with antioxidant activities ${ }^{[12]}$. In this study, 16 phenolic compounds were isolated from $P$. urinaria, most of which contained two or more phenol groups. In phytochemistry, these can in detail be classified into anthraquinone (compound 1), flavanols (2 and 3), phenolic acids $(10,11$ and 16$)$ or phenolic derivatives $(4,5,8,9$ and 12), phenylpropanoids $(6,13-15)$, and lignin (7).

In ORAC and DPPH assay, all compounds nearly exhibited different levels of ORAC and radical scavenge capacity, in which most of the tested compounds exhibited strong ORAC and the DPPH scavenging $\mathrm{IC}_{50}$ values were determined using dose-response curves. ORAC, DPPH assay demonstrated that these phenols exhibited good antioxidant activities. Among these polyphenols, the phenolic acids 3-O-methylgallic acid (11) showed significant activity both in the antioxidant and antivirus assays compared to other phenolic acids such as gallic acid (10), ethyl gallate (12) and protocatechuic acid (16). As to the antiviral activity, previous studies showed the gallate structure played a critical role in the inhibition of HBV activity ${ }^{[40]}$. In the antiHBV assay, the 3-O-methylgallic acid (11) and protocatechuic acid (16), especially the ethyl gallate (12) exhibited remarkable antiviral capacity.

Oxidative stress can result from increased production of reactive oxygen species (ROS). To maintain a proper redox balance, excrescent ROS may be scavenged, and the activities of oxidant enzyme may be diminished ${ }^{[41]}$. The antioxidant activities of polyphenols mainly stem from their ROS scavenging on the oxidative stress injury. Previous studies revealed that the effect of HBV on the host antioxidant system and Fas-signalling is a crucial factor in the development of hepatocellular carcinoma, because the change of antioxidant enzyme

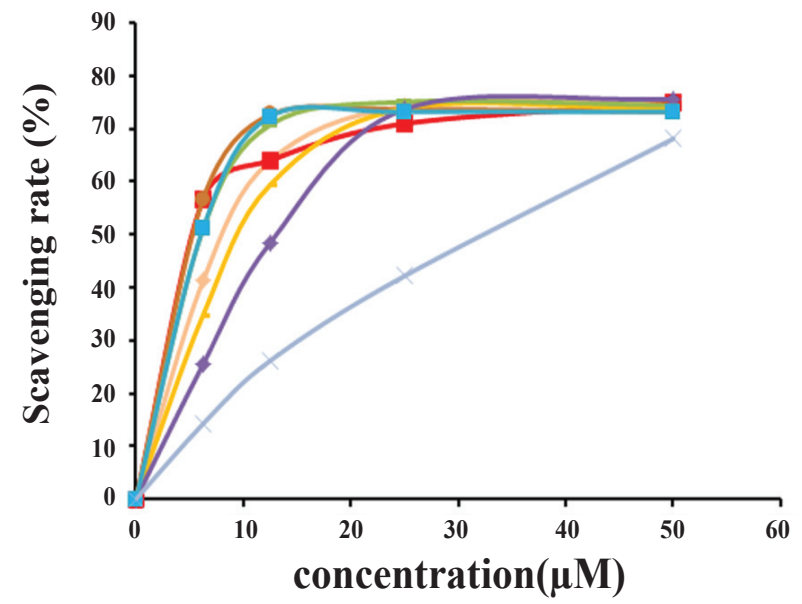

Fig. 3: Dose-response curves in the DPPH radical scavenging assay

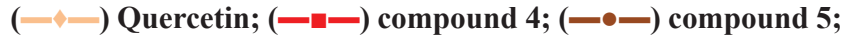
$(-)$ compound 9 ; $(-)$ compound 10 ; $(-\bullet)$ compound 11; (-匹-) compound 12 ; $\left(-^{*}-\right)$ compound 16 
system sensitized the HBV transgenic mice to the Fas signaling pathway ${ }^{[42]}$. Furthermore, the ROS levels mediated by HBV X proteins were down-regulated by the treatment with antiviral drugg ${ }^{[43]}$.

Therefore, the antioxidant activities of phenolic compounds from $P$. urinaria may relate to the antiHBV activities, such as the compounds 2, 4, 5 and 11 not only shown strong antioxidant activity but also significant antiviral activity. Besides, among these polyphenols, 3-O-methylgallic acid (11) showed prominent biological actions both in antioxidant and antiviral activities comparing with the gallic acid (10), ethyl gallate (12) and protocatechuic acid (16). These finding suggested that the phenols from $P$. urinaria may play an important role in antihepatitis activities and the antiHBV effect of $P$. urinaria may relate to its antioxidative activities.

\section{Financial interest and scholarship:}

This research was financially supported by the grant (JCYJ20150401163247220) of Shenzhen Science and Technology Project of Shenzhen of China and the grant (No.81774263) of National Natural Science Foundation of China, and Project of Quality Standard for Chinese Materia Medica, Library for Chemical Constituents, National Administration Bureau of Chinese Medicine.

\section{REFERENCES}

1. Calixto JB, Santos AR, Cechinel FV, Yunes RA. A review of the plants of the genus Phyllanthus: their chemistry, pharmacology, and therapeutic potential. Med Res Rev 1998;18(4):225-58.

2. Thyagarajan SP, Subramanian S, Thirunalasundari T, Venkateswaran PS, Blumberg BS. Effect of Phyllanthus amarus on chronic carriers of hepatitis B virus. Lancet 1988;2(8614):764-6.

3. Fang SH, Rao YK, Tzeng YM. Anti-oxidant and inflammatory mediator's growth inhibitory effects of compounds isolated from Phyllanthus urinaria. J Ethnopharmacol 2008;116(2):333-40.

4. Lin SY, Wang CC, Lu YL, Wu WC, Hou WC. Antioxidant, anti-semicarbazide-sensitive amine oxidase, and antihypertensive activities of geraniin isolated from Phyllanthus urinaria. Food Chem Toxicol 2008;46(7):2485-92.

5. Cheng HY, Yang CM, Lin TC, Lin LT, Chiang LC, Lin CC. Excoecarianin, isolated from Phyllanthus urinaria Linnea, inhibits herpes simplex virus Type 2 infection through inactivation of viral particles. Evid-based Compl Alt Med 2011;2011(5):296-7.

6. Shin MS, Kang EH, Lee YI. A flavonoid from medicinal plants blocks hepatitis B virus-e antigen secretion in HBV-infected hepatocytes. Antiviral Res 2005;67(3):163-8.

7. Chung CY, Liu CH, Wang GH, Jassey A, Li CL, Chen L, et al. (4R,6S)-2-Dihydromenisdaurilide is a butenolide that efficiently inhibits hepatitis $\mathrm{C}$ virus entry. Sci Rep 2016;6:29969.

8. Zhong Y, Zhang QG. Studies on chemical constituents of Phyllanthus urinaria L. and its antiviral activity against hepatitis B virus. Zhongguo Zhong Yao Za Zhi 1998;23(6):363-4.

9. Zhang LZ, Guo YJ, Tu GZ, Miao F, Guo WB. Isolation and identification of a novel polyphenolic compound from Phyllanthus urinaria L. Zhongguo Zhong Yao Za Zhi 2000;25(12):724-5.

10. Chang CC, Lien YC, Liu KCSC, Lee SS. Lignans from Phyllanthus urinaria. Phytochemistry 2003;63(7):825-33.

11. Zhang LZ, Guo YJ, Tu GZ, Guo WB, Miao F. Isolation and identification of a novel ellagitannin from Phyllanthus urinaria L. Yao Xue Xue Bao 2004;39(2):119-22.

12. Wei CS, Wu C, Hu C, Liang QP, Tong GD, Zhou GX. Chemical constituents of flavonoids from Phyllanthus urinaria and their activities. Nat Prod Res Dev 2017;12:2056-62.

13. Erden IM, Kahraman A. The protective effect of flavonol quercetin against ultraviolet a induced oxidative stress in rats. Toxicology 2000;154(3):21-9.

14. Alía M, Mateos R, Ramos S, Lecumberri E, Bravo L, Goya L. Influence of quercetin and rutin on growth and antioxidant defense system of a human hepatoma cell line (HepG2). Eur J Nutr 2006;45(1):19-28.

15. Kamalakkannan N, Prince PS. Antihyperglycaemic and antioxidant effect of rutin, a polyphenolic flavonoid, in Streptozotocin-induced diabetic Wistar rats. Basic Clin Pharmacol Toxicol 2006;98(1):97-103.

16. Devipriya N, Srinivasan M, Sudheer AR, Menon VP. Effect of ellagic acid, a natural polyphenol, on alcohol-induced prooxidant and antioxidant imbalance: a drug dose dependent study. Singapore Med J 2007;48(4):311-8.

17. Chen HM, Wu YC, Chia YC, Chang FR, Hsu HK, Hsieh YC, et al. Gallic acid, a major component of Toona sinensis leaf extracts, contains a ROS-mediated anti-cancer activity in human prostate cancer cells. Cancer Lett 2009;286(2):161-71.

18. Londhe JS, Devasagayam TP, Foo LY, Ghaskadbi SS. Antioxidant activity of some polyphenol constituents of the medicinal plant Phyllanthus amarus Linn. Redox Rep 2013;13(5):199-207.

19. Xu JK, Yao XS, Kurihara H. Oxygen radical absorbance capacity assay and its application. Chin Pharmacol Bull 2006;22(8):1015-21.

20. Grajeda-Iglesias C, Salas E, Barouh N, Baréa B, Panya A, Figueroa-Espinoza MC. Antioxidant activity of protocatechuates evaluated by DPPH, ORAC, and CAT methods. Food Chem 2016;194:749-57.

21. Zhou ZQ, Xiao J, Fan HX, Yu Y, He RR, Feng XL, et al. Polyphenols from wolfberry and their bioactivities. Food Chem 2017;214:644-54.

22. Zhang X, Thuong PT, Jin W, Su ND, Sok DE, Bae K, et al. Antioxidant activity of anthraquinones and flavonoids from flower of Reynoutria sachalinensis. Arch Pharm Res 2005;28(1):22-7.

23. Ding G, Liu YZ, Wang L, Ji CR, Sheng LS. Main hydrolysable tannins from Terminalia chebula. J Chin Pharm Univ 2001:32(2):91-3.

24. Jung MJ, Kang SS, Jung YJ, Choi JS. Phenolic glycosides from the stem bark of Albizzia julibrissin. Chem Pharm Bull 2004;52(12):1501-3.

25. Gan M, Zhang Y, Lin S, Liu M, Song W, Zi J, et al. Glycosides from the root of Iodes cirrhosa. J Nat Prod 2008;71(4):647. 
26. Xie LH, Akao T, Hamasaki K, Deyama T, Hattori M. Biotransformation of pinoresinol diglucoside to mammalian lignans by human intestinal microflora, and isolation of Enterococcus faecalis strain PDG-1 responsible for the transformation of $(+)$-pinoresinol to $(+)$-lariciresinol. Chem Pharm Bull 2003;51(5):508-15.

27. Bai N, He K, Roller M, Zheng B, Chen X, Shao Z, et al. Active compounds from Lagerstroemia speciosa, insulinlike glucose uptake-stimulatory inhibitory and adipocyte differentiation-inhibitory activities in 3T3-L1 cells. J Agric Food Chem 2008;56(24):11668-74.

28. Shi XH, Du XL, Kong LY, Du XL, Kong LY. Studies on chemical constituents in roots of Euphorbia soongarica. Zhongguo Zhong Yao Za Zhi 2006;31(18):1503-6.

29. Deng AJ, Qin HL. Studies on chemical constituents of fruits of Bridelia tomentosa. Zhongguo Zhong Yao Za Zhi 2008;33(2):158-60.

30. Yang J, Yang XD, Yang S, Zhao JF, Li L. Chemical study on Glochidion hirsutum (II). Nat Prod Res Dev 2007;19(6):9868.

31. Yi JH, Chen Y, Li BG, Zhang GL. Studies on the chemical constituents of the tubers of Curcuma longa. Nat Prod Res Dev 2003;15(2):98-100.

32. Zheng D, Zhang XQ, Wang Y, Ye WC. Chemical constituents of the aerial parts of Blumea riparia. Chin J Nat Med 2007;5(6):421-4.

33. Yang Y, Li SG, Ye WC, Jiang RW. Studies on chemical constituents of Microcos paniculata. Lishizhen Med Mater Med Res 2010;21(11):2790-2.

34. Yang CM, Cheng HY, Lin TC, Chiang LC, Lin CC. Acetone, ethanol and methanol extracts of Phyllanthus urinaria inhibit HSV-2 infection in vitro. Antiviral Res 2005; 67:24-30.

35. Mohammad NA, Gayathri M. Analysis of anti-diabetic properties of Phyllanthus urinaria by docking studies. Der Pharm Lett 2015;7(12):132-7.

36. Agyare C, Spiegler V, Herbert S, Asase A, Eva L, Hensel A. An ethnopharmacological survey and in vitro confirmation of the ethnopharmacological use of medicinal plants as anthelmintic remedies in the Ashanti region, in the central part of Ghana. J Ethnopharmacol 2014;158:255-63.

37. Chung CY, Liu CH, Burnouf T, Wang GH, Chang SP, Jassey A, et al. Activity-based and fraction-guided analysis of Phyllanthus urinaria identifies loliolide as a potent inhibitor of hepatitis C virus entry. Antiviral Res 2016;130:58-68.

38. Wang GF, Shi LP, Ren YD, Liu QF, Liu HF, Zhang RJ, et al. Anti-hepatitis $\mathrm{B}$ virus activity of chlorogenic acid, quinic acid and caffeic acid in vivo and in vitro. Antiviral Res 2009;83(2):186-90.

39. Dayem AA, Choi HY, Yang GM, Kim K, Saha SK, Cho SG. The anti-cancer effect of polyphenols against breast cancer and cancer stem cells: Molecular mechanisms. Nutrients 2016;8(9):581.

40. Lee SJ, Lee HK, Jung MK, Mar W. In vitro antiviral activity of 1,2,3,4,6-penta-O-galloyl-beta-D-glucose against hepatitis B virus. Biol Pharm Bull 2006;29(10):2131-4.

41. Shen Y, Zhang H, Cheng L, Wang L, Qian H, Qi X. In vitro and in vivo antioxidant activity of polyphenols extracted from black highland barley. Food Chem 2016;194:1003-12.

42. Wang Q, Na B, Ou JH, Pulliam L, Yen TS. Hepatitis B virus alters the antioxidant system in transgenic mice and sensitizes hepatocytes to Fas signaling. PLoS One 2012;7(5):e36818.

43. Zhang S, Gao S, Zhao M, Liu Y, Bu Y, Jiang Q, et al. AntiHBV drugs suppress the growth of HBV-related hepatoma cells via down-regulation of hepatitis $\mathrm{B}$ virus $\mathrm{X}$ protein. Cancer Lett 2017;392:94. 